\title{
Developing Medical Virtual Teaching Assistant Based on Speech Recognition Technology
}

\author{
https://doi.org/10.3991/ijoe.v17i04.21343 \\ Dwijoko Purbohadi $\left({ }^{\bowtie}\right)$, Silvia Afriani, Nicko Rachmanio, Arlina Dewi \\ Universitas Muhammadiyah Yogyakarta, Bantul, Indonesia \\ purbohadi@yahoo.com
}

\begin{abstract}
This paper proposes to present the results of the development of the Virtual Teaching Assistant (VTA). This system is an e-learning module as a learning aid for medical students currently pursuing professional medical doctor in hospitals. In Indonesia, students of the medical doctor profession education must study and work in hospitals like an experienced doctor. They interact directly with patients and provide the same services as doctors. Every student has a professional doctor at the hospital as a mentor or companion. However, student meetings with accompanying doctors are minimal. It is not uncommon for students to encounter difficulties when dealing with patients, but they do not immediately receive guidance. As students, it is natural that they sometimes forget the theory. These students need a theoretical learning source that is fast and practical, which students can use between activities. We developed VTA to meet the needs of information and fast learning resources. VTA can run on computer, laptop, or smartphones by utilizing speech recognition technology. Students only need to ask questions in the form of speech using their everyday language, and VTA will provide answers. Although the VTA answer is still not satisfactory, it potentially to support Question and Answer-based mobile learning for particularly learning subject.
\end{abstract}

Keywords - Rivescript, speech recognition, virtual teaching assistant

\section{$1 \quad$ Introduction}

In Indonesia education system, one part of the medical education program is a profession program known as the Medical Doctor Profession Education Program. This programs in medical education are carried out in clinical learning and community learning with various levels and forms of health services aimed at meeting student competencies before being declared a doctor [1]. The Medical Doctor Profession Education Program uses a four-semester system. This program is an advanced program for students who have completed the undergraduate medical education program.

The student learning process at the professional stage uses the Indonesian Doctor Competency Standards set by the Indonesian Medical Council (IMC). Profession Education aims to provide opportunities for students to understand the theory, train clinical skills, clinical procedures, and train seven areas of doctor competence [2]. Using the 
purpose and system of IMC, educational institutions hope that every profession education graduate can use their knowledge and skills in the future society ethically and manage individual and community health for both promotive, preventive, and curative actions and can improve knowledge for themselves nor society. Professional education and training therefore needs to make an active contribution to the conditions that students have to developing their skills of critical reflection [3].

Following a profession program means entering a real-world filled with clinical rotational activities. We cannot deny that students face many challenges, not only challenges in applying knowledge and skills. Adaptation to a clinical learning culture, assumptions about greater responsibility, processes requiring higher self-learning abilities, and ongoing processes for adapting to new people, changing places, materials, and expectations placed on them. In clinical rotations, students take learning in departmental stages that require continuous adjustment. The lecturers' role is crucial in creating a learning environment that can support students' learning process at this professional stage. In this phase, it has the potential to cause problems for students, especially causing stress [4].

One of the most frequent stressors for students who attend profession education is the change in the learning environment from being in the classroom to being in the hospital. Students will experience difficulties when in the hospital. After all, they cannot work because they do not understand science; this can happen when students feel that their knowledge is lacking and when they want to consult with experts, it is also not possible because time is minimal. Students feel as if there is not enough time to learn everything [5]. Often students find patients with complaints of certain diseases; that is when students feel they need further information about the disease. Students need instant answers such as where the disease's location is, how to treat it, whether the patient's symptoms are the same as the theory taught, or whether the patient need a laboratory examination. Carrying a lecturing notebook or searching for information on the internet using computer or laptop is not a solution that provides speed and practicality. Today, students know that e-book providing sufficient information to meet educational needs [6]. Therefore, profession education's learning process requires a system or tool that can help improve knowledge instantly using smartphone so that learning activities in the hospital become effective. All students always bring their smartphone anytime and anywhere.

In the developing countries like Indonesia, is required in the ways education is delivered to the 'digital natives' of today and tomorrow [7]. We should introduce technology in context [8]; that is why we designed a virtual teaching assistant or VTA (Virtual Teaching Assistant), a study aid system for medical students based on speech recognition technology. The primary purpose of VTA is as a learning aid for medical profession education students. VTA offer the opportunity to improve the learning experience and the quality of teaching, both in the case of online and on-site courses [9]. We hope that this VTA can increase students' knowledge of medical science, increase self-awareness, and instantly add insight. Students only need to express problems or questions faced in everyday language by using this voice recognition technology. The system will process the voice to find the student's core questions. When a core question is successfully detected, the system immediately searches a database of relevant answers. 
The main obstacle in using speech recognition technology to be processed into information is related to the use of Indonesian in everyday conversation itself. In Indonesia, in everyday life the use of Indonesian no longer pays attention to standard grammar, often uses slang, even vocabulary that comes from regional languages often appears. Indonesian is very easy to learn and easy to use for daily communication, however for official written language it becomes very complicated. There are many challenges in using formal Indonesian so that people prefer to use informal language in daily communication, including in official jobs [10].

\section{Language and Speech Recognition}

There are two interrogative sentences in the Indonesia language: the confirmative sentence and the informative interrogative sentence. A confirmative question sentence is an interrogative sentence that requires a yes, no, or not answer. Informative question sentences are interrogative sentences that require explanation. In this study, we used informative sentences because the primary function of VTA is to process questions from medical students who need explanation. This study aims to develop a learning aid system for medical profession students by linking student difficulties with technology, between student questions and instant answers, and between everyday language and knowledge databases. Thus, VTA must have the primary ability to capture everyday language to be processed into keywords to search for information in the database.

\subsection{Bahasa Indonesia structure}

According to the Indonesian Dictionary or KBBI (Kamus Besar Bahasa Indonesia), a sentence is a language unit that can stand alone, have a tone, and consist of Indonesian clauses. Sentences have various structures to differentiate them. Sentences also have various uses, namely formal and non-formal sentences. Formally sentences are sentences written based on excellent and correct Indonesian rules. Because formal language is rigid, people rarely use formal sentences in everyday conversation. In daily communication, non-formal language is more intensively used because they are more practical and easier to understand [11]. We often encounter formal sentences in speeches, official events, official documents, or in scientific writing. Of course, the formal sentence has a very stiff main character.

On the other hand, non-formal sentences are sentences that deviate from grammar rules and tend to use slang. This sentence useful in everyday conversations between peers. In Indonesia, non-formal sentences are very diverse and highly influenced by local languages, so that words often appear that are not in the Indonesian dictionary. People used mix language between local language with Indonesia language at daily activity [12]. Seeing cases like this, VTA must have the ability to process these nonformal sentences. Seeing cases like this, VTA must be able to process these non-formal sentences. Table 1 shows the standard structure of complete sentences in Indonesian. This table also shows the relationship between the standard structure and the question words used. 
Table 1. Question word list in Indonesia Language

\begin{tabular}{|l|l|l|}
\hline \multicolumn{1}{|c|}{ Question word } & \multicolumn{1}{|c|}{ Translate } & \multicolumn{1}{c|}{ The object in question } \\
\hline What & Apa & Objects, animals, plants, and identities \\
\hline Who & Siapa & The perpetrator \\
\hline Why & Mengapa & Reasons and causes \\
\hline How & Bagaimana & Circumstances, processes, or means \\
\hline Where & Dari mana, ke mana, dimana & Location, origin, or destination \\
\hline When & Kapan & Time and terms \\
\hline How many, how much, how long, & Berapa & Number or value \\
\hline etc. & & \\
\hline
\end{tabular}

\subsection{Unformal interrogative sentences}

In formal Indonesian language, we use the Subyek-Predikat-Obyek-Keterangan or SPOK structure. From this structure, we can make interrogative sentences using question words. For asking the subject, we are using "siapa," to ask the predicate using the question word "apa", to ask the object using "siapa", and to ask information using the question word "mengapa, berapa, dimana, berapa, bagaimana". Often, we add "kah" to a question word, like "apa" becomes "apakah", likewise, for other question words. There is no structure in a non-formal interrogative sentence; even the arrangement can be very changing and random. Even the word question changed to use slang or local language. Formally the question word "apa" changes to "apakah" as in the case to form a confirmative interrogative sentence. However, in slang, it changes to "apa" or "apaan". Likewise, the question word "bagaimana" often changes to "gimana" or "gimana sih". It is not uncommon for Javanese language influences to appear, such as the use of the word "to", so that "apa" becomes "apato" or "apa to". Three factors influence language variations in Indonesia: social factors, cultural, and situational.

\subsection{Core question detection}

We designed VTA using word recognition technology developed and tested from official languages. In principle, this voice recognition technology converts the voice into a text structure that matches the official language's words [13]. However, from our testing, this technology scan recognizes several words from local languages, especially Javanese. We cannot rely on formal language as the basis for VTA development because it is impossible to lead students to use specific interrogative sentences. There is one exciting thing; this voice recognition technology can produce different texts for the same pronunciation.

Because people use slang or local words in their daily interrogative sentences, the sentence structure cannot be determined, and the number of words is uncertain. We conclude that to detect non-formal interrogative sentences cannot using a structural approach. In this study, we used a basic word type approach. We divide words into three types, namely question words, predicates, and objects. This division has nothing to do with the interrogative sentence structure in standard Indonesian language structure, but this is our way of constructing the core of the questions related to the database's search 
mechanism. Figure 1 shows the concept of the word approach for core question detection.

\begin{tabular}{|c|c|c|}
\multicolumn{1}{c|}{ Daily speaking } & VTA technology \\
$\begin{array}{c}\text { Unstructured, slang, } \\
\text { deviate, random word } \\
\text { (number), and locally }\end{array}$ & $\longrightarrow \begin{array}{c}\text { VTA Structure } \\
\text { Speech Recognition and } \\
\text { Words Processing }\end{array}$ & $\begin{array}{c}\text { Question word + Predicate } \\
\text { + Object }\end{array}$ \\
\hline
\end{tabular}

Fig. 1. The concept of sentence processing uses a word approach.

Because users use question sentences that are unstructured, distorted, use irregular words, random numbers, and are local, we design VTA can detect the essence of the question in the form of a Question Word-Predicate-Object. The detection process uses speech recognition technology, rive script, filtering, sorting, and word distance measurement. One limiting the tool's work is that the question must contain terms in medical science as objects. The existence of the object of the question becomes the basis for finding related answers.

\section{$3 \quad$ Language and Speech Recognition}

TA uses a web-based architecture to ensure that the interaction between applications, databases, and middleware systems on the web can produce a system with many users who can access simultaneously. Because VTA is related to learning activities for profession program students, we designed an architecture to optimize the function of the e-learning system (Learning Management System or LMS). Figure 2 shows the VTA system architecture integrated into the LMS environment. However, we designed VTA so that graduates can access freely without having to go through the LMS, they can access it using the Mobile Application.

Architecturally, VTA is part of an LMS system so a teacher can monitor their student activity when using the application. Technologically, VTE has software tools consisting of a voice to text converter, rive script, a word processing algorithm, a data search algorithm, a word distance meter, and a text to voice converter. The VTA uses a hardware microphone, display, and loudspeaker. The main principle works of VTA is like chatbot, but we design this architecture because the chatbot is not capable of free conversations [14]. 


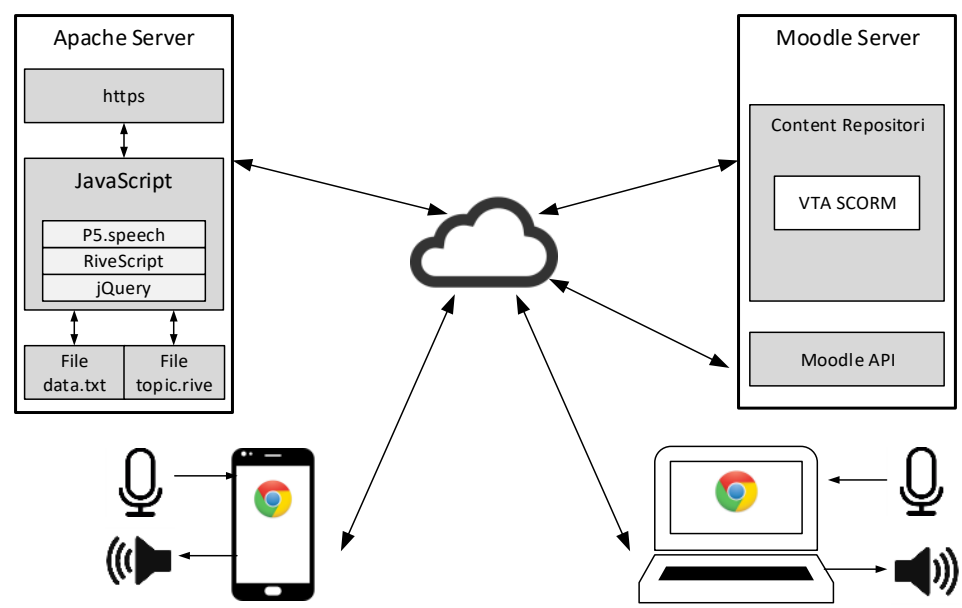

Fig. 2. Virtual Teaching Assistant Architecture

\subsection{RiveScript}

RiveScript or Artificial Intelligence Scripting Language is an implementation of a line-based scripting language [15]. RiveScript is open-source software with an interface for many programming languages such as Python, Java, or JavaScript.

In RiveScript syntax, the ' + ' symbol indicates input; in this case, the input comes from speech to text form. Meanwhile, the symbol "-" "indicates the chatbot response. The Interpreter section matches user input with an algorithm or logic to determine the most suitable reaction. RiveScript also defines wildcards, conversation redirects, and chatbot variables. The * symbol is a symbol to represent any word, and the <star> is a symbol to determine the position of the selected words in a sentence [16].

VTA uses RiveScript to select words related to the topic of knowledge that we searched. Each interrogative sentence in the form of text will go through the translation process through a sequence of scripts so that the selected words appear. By the VTA design, choosing the words to look for is by sorting question words, predicates, and terminology. The words are very random in location, order, even shape. So, we create a rive script file with the following basic form:

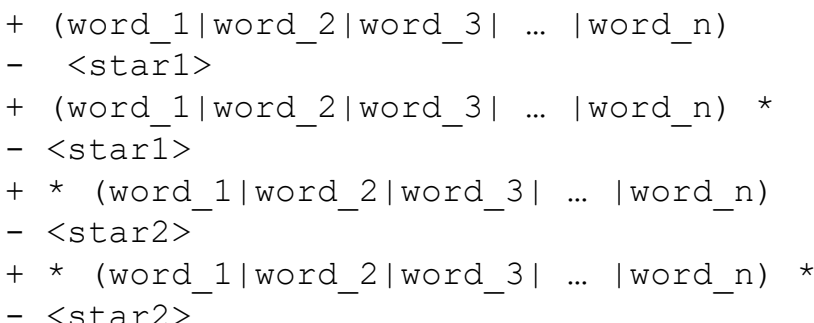


The writing of the RiveScript represents several similar words from 1 to $\mathrm{n}$. Symbol "+" has meaning as input, symbol "-" for output, symbol "()" to represent the choice of words, symbols and symbols "|" has a logical meaning "OR." The symbol "<star>" has a role in determining a searched word's position in a sentence, whether at the beginning, middle, or end.

\subsection{Levenshtein algorithm}

The Levenshtein algorithm is a distance measure due to the development of a scientist who came from Russia in 1965 named Vladimir Levenshtein [17]. Programmers are more familiar with Levenshtein for measuring the distance between two strings. The distance of two strings is the minimum number of edits to convert one string to another $\mathrm{r}[18]$. Levenshtein's distance algorithm is beneficial for applications used in determining the similarity of two strings [19]. Levenshtein's distance algorithm is an algorithm editor that utilizes dynamic programming strings to operate an application [20]. Levenshtein distance is the minimum distance required to convert one string to another. Levenshtein distance is a simple metric which can be an effective string approximation tool [21].

We used the Levenshtein algorithm to match or search for the closest words between the question identification results against a database of word lists of medical terms. We use this algorithm so that VTA does not have rigid properties. By using this approach to the concept of closeness, VTA still provides information or answers that are close to the core of the question of the knowledge.

Table 2. Arrangement of columns to compile a list of questions and answer

\begin{tabular}{|l|l|l|l|l|}
\hline Qword & Predicate & \multicolumn{1}{|c|}{ Object } & \multicolumn{1}{c|}{ Question } & \multicolumn{1}{c|}{ Answer } \\
\hline Apa & Definisi & Buli-buli & Apa definisi buli-buli & Buli-buli adalah \\
\hline Dimana & Terjadi & $\begin{array}{l}\text { Pebesaran saluran } \\
\text { kemih }\end{array}$ & $\begin{array}{l}\text { Dimana terjadi pembesaran } \\
\text { saluran kemih }\end{array}$ & $\begin{array}{l}\text { Pembesaran salurann } \\
\text { kemih terjadi di seki- } \\
\text { tar }\end{array}$ \\
\hline Kapan & Pegobatan & Infeksi & Kapan pengobatan infeksi & $\begin{array}{l}\text { Pengobatan infeksi } \\
\text { dapat dilakukan }\end{array}$ \\
\hline
\end{tabular}

VTA stores knowledge in the form of a JSON file. We incorporate elements of medical knowledge through the process of moving from books to digital form. In principle, we can convert the book's entire contents into digital data, but we only include sentences with full meaning or core information. We use book summaries because VTA aims to support profession medical program students who need instant answers. Although in principle, we can enter all the contents of the book into this system.

We made a summary using Microsoft Excel using four columns, as shown in Table 2. The amount of information in the book determines the number of rows.

This list becomes the knowledge stored in the database using the JSON format as shown in Figure 3. 


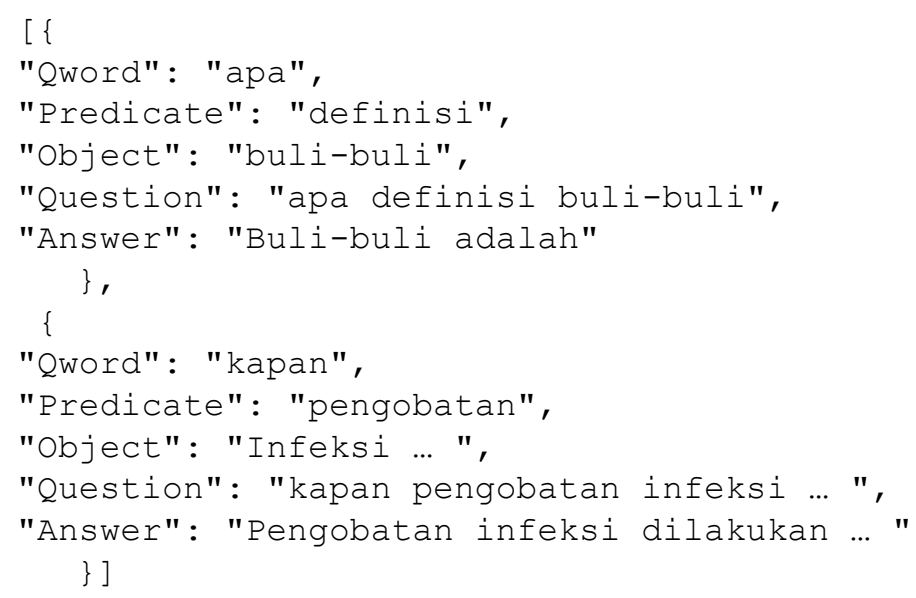

\section{Result}

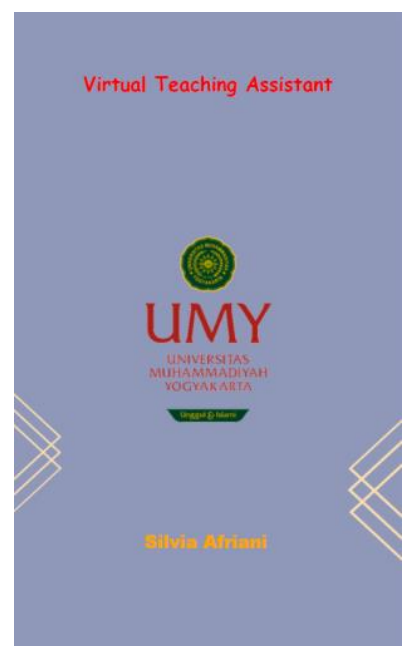

The main page

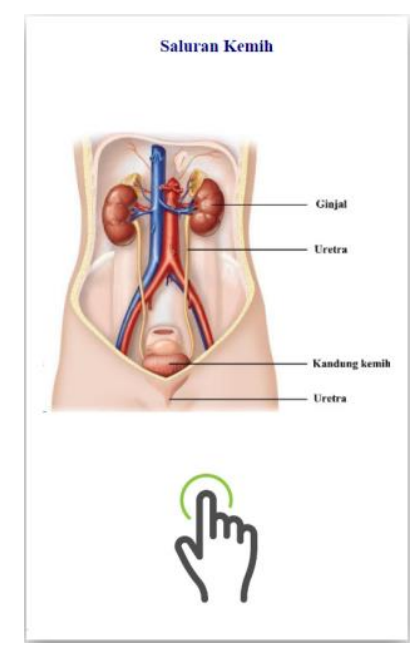

Topic page

Fig. 3.

Figure 3 shows the speech recognition-based learning assistant main and topic page; when the program is first to run, the main page appears, then the topic title. In this experiment, we tested the application under one topic title, namely the urinary tract.

Figure 4 is the next page display, which is a Virtual Teaching Assistance display according to the selected category. The process executed in this display is pressing the start button to start so that the display appears. 


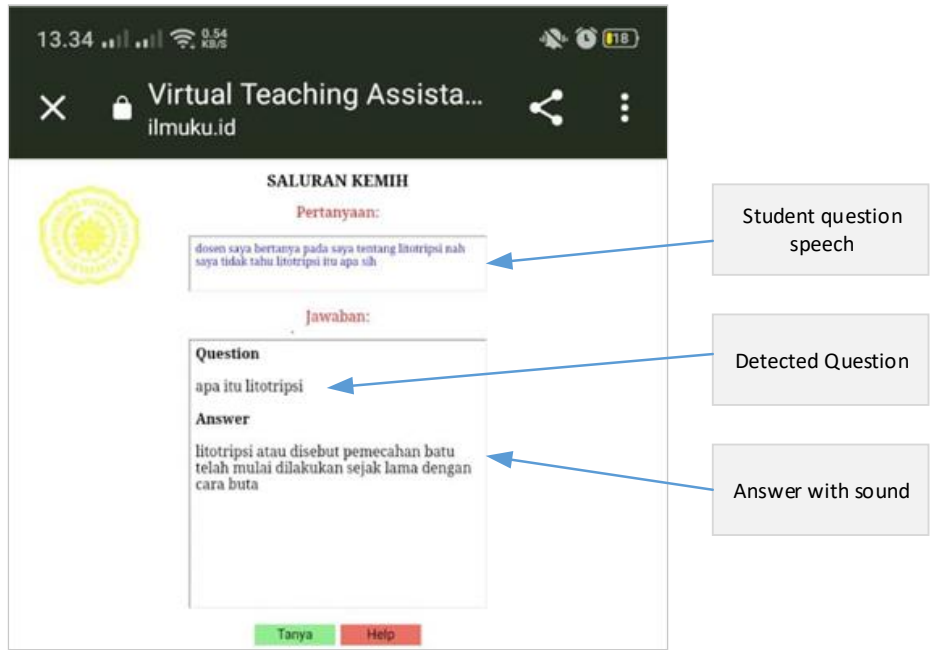

Fig. 4. Virtual Teaching Assistant (VTA) response

We tested VAT for urinary tract topics by taking material from lecture handbooks. We managed to compile 137 lines of the book's digest. Table 3 shows the details of the material.

Table 3. . Summary list of questions

\begin{tabular}{|l|c|l|}
\hline \multicolumn{1}{|c|}{ Element } & Number & \multicolumn{1}{c|}{ Explanation } \\
\hline Total number of the question - answer & 137 & \\
\hline The question with the word "apa" & 80 & Asking the definition \\
\hline The question with the word "apa saja" & 5 & Asking the detail or list \\
\hline The question with the word "dimana" & 12 & Asking the place of diseases \\
\hline The question with the word "kapan" & 5 & Asking time for a treatment \\
\hline The question with the word "bagaimana" & 18 & Asking on how to do \\
\hline The question with the word "berapa" & 2 & Asking on age \\
\hline The question with the word "mengapa" & 12 & Asking reason of a case \\
\hline The question with the word "siapa" & 3 & Asking who has high risk \\
\hline Total definition unrecognized & 2 & Conversions don't match \\
\hline
\end{tabular}

\section{Discussion}

The purpose of developing a voice recognition application-based learning assistant is as a learning tool for medical education students and a tool to make it easier for medical education students to find data or knowledge information more quickly and only using voice commands. Therefore, we hope that through this method, students will find it helpful after using VTA. Indeed, VTA is not suitable for all conditions or situations. We designed it so that VTA is perfect for helping students who need instant, straightforward answers. This method is very beneficial for eliminating small things 
such as forgetting terms, methods, or symptoms that can create new problems for the students. Figure 3 is a VTA diagram after going through testing and refinement.

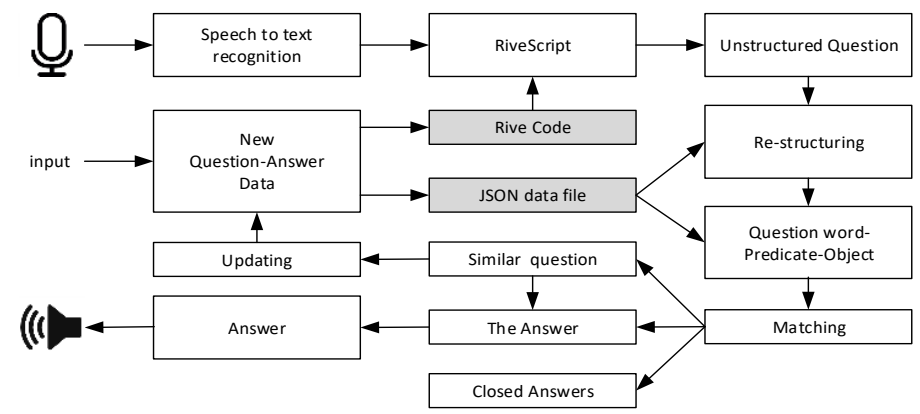

Fig. 5. Block Diagram of VTA Software

\subsection{The concept of finding the answer}

The conceptual design of data search in this learning assistant uses the relationship between questions and answers. In principle, the application will process questions to find answers using speech to text technology, RiveScript, sequencing, matching, and searching. So, the detection result of the question will determine the form of the answer. Table 4 provides a breakdown of four possible VTA responses.

Table 4. Possible VTA response on questions

\begin{tabular}{|l|l|l|l|}
\hline Question Word & Predicate & \multicolumn{1}{|c|}{ Object } & \multicolumn{1}{c|}{ Response } \\
\hline$*$ & $*$ & No & The question was not detected \\
\hline$*$ & No & Yes & $\begin{array}{l}\text { displays all data which is like or equal to the question ob- } \\
\text { ject. }\end{array}$ \\
\hline No & Yes & Yes & displays a selection of similar questions \\
\hline Yes & Yes & Yes & answer and speak \\
\hline
\end{tabular}

There are four types of questions, namely:

1. The intonation used.

2. The negation used is the words no, no, or not.

3. Sometimes using the word is there or whether.

4. Using the "kah" particle.

The second type of question uses question words: what, who, how, why, how much, when, and so on. We have not included VTA's ability to respond to interrogative sentences using intonation because speech to text technology cannot detect sound intonation differences. We also have not developed a VTA to recognize yes or no questions because processing these types of questions requires a more complex algorithm in Indonesian. In this study, we only handled interrogative sentences that used interrogative words to obtain information. 


\subsection{Accuracy of VTA}

Theoretically, speech recognition technology has an accuracy of up to 98\% [22]. The accuracy of VTA decreases because there is an interrogative sentence processing process to produce information. Even though it matches sentences in nature, the accuracy still decreases. In this study, we used a measure whereby the information that corresponds to the question becomes the VTA's accuracy. The overall accuracy rate of VTA in the early stages of development was 59\%. We found the causes for this drop in numbers, namely:

1. The use of loan terms from English does not read correctly, such as "dam glen" read "dam glass", two sentences that have very different meanings.

2. The object of the question was not found because of the use of regional languages.

3. Republished words in Indonesian are written in the double with a minus sign, but voice recognition detects a connecting line sometimes.

4. The matching with the Levenshtein algorithm results in a small distance measure, but the meaning is much different.

5. When using VTA, it should be in a quiet place. External noises are sometimes picked up by the microphone, affecting the results, especially when an external sound causes the loss of a question word, predicate, or object.

To anticipate this low accuracy rate, we added a function to display alternative questions close to what students are asking. Also, we added the VTA's ability to display information or answers related to the question's object. This method is to reduce the level of student confidence in VTA.

\subsection{Research limitation}

The results of this study are closely related to the topic of urinary tract learning, wherein this concept we create a question model to make it easier for students to find answers related to smaller topics, namely types of disease, diagnosis, treatment, definitions, symptoms, location of illness, causes of infection, examination, and the patient's physiological condition. For other topics, it is likely to have more small topics. If we increase the topics, the number of objects and predicates on the question will also increase. We have not equipped the VTA with features to add data. Thus, we cannot provide exact figures for the accuracy of the system.

Although learning resources and materials in medical education continue to develop, new problems arise in practical learning in hospitals, including finding sources of information. We have explained before that the purpose of creating a VTA is to provide easy access to the subject matter, especially to find answers quickly, concisely, and clearly. In this study, we focus only on the accuracy of VTA.

\subsection{Student response and future work}

We allow two students to try VTA. From the interview, we obtained several meaningful responses as follows: 
1. Students see VTA results that are better at answering questions than Google. If they use Google, too many choices and have to read much text to find answers. VTA is more focused and concise.

2. VTA gave an answer that was too short, so it needs a button to display more detailed information.

3. Regarding the critical question "does VTA help students?", They gave positive responses even though VTA had not been able to detect the core of the question as they expected.

4. From this preliminary development, testing, and testing, we have had very positive results. Future research will improve accuracy, add multiple topics, and conduct experiments on actual learning in profession medical programs.

\section{Conclusion}

We found several things that were important for VTA development, namely:

1. The audio system's quality and environmental conditions significantly affect the sound and ultimately affect the text conversion results. Also, environmental conditions sometimes force the user to repeat the question. The filtering process using RiveScript works perfectly, so in this part we keep for the next development.

2. Because the non-formal interrogative sentence structure is very random, the interrogative sentence uses words or terms taken from foreign languages, and users use mixed languages, causing the detection process to involve much if-then-else logic. If we did not include a specific question in the if-then-else algorithm, the system could not find an answer. This condition causes VTA's performance to decline.

3. The process of finding answers that match the word approach can work well, but the parameters of sentence proximity still require experimentation to find the optimal number. How to summarize the book and construct the interrogative sentences affects the final result. To improve the ability to answer requires the development of architecture and algorithms.

4. In this research, we prove that the basic word approach is very potential for the development of speech recognition technology applications for VTA.

\section{$7 \quad$ Acknowledgement}

We want to thank the UMY research institute's leadership for providing funds through the Muhammadiyah University of Yogyakarta Collaborative Research Program for the 2019/2020 budget year.

\section{$8 \quad$ References}

[1] Y. Mahendradhata et al., The Republic of Indonesia Health System Review, vol. 7, no. 1. 2017. 
[2] R. N. Hidayah, "Impact of the national medical licensing examination in Indonesia: perspectives from students, teachers, and medical schools," no. February, p. 244, 2018.

[3] S. Gustavsson, A. Andersén, and M. Berglund, "To challenge and to be challenged-teachers collective learning in higher education," Reflective Pract., vol. 20, no. 3, pp. 339-354, 2019, https://doi.org/10.1080/14623943.2019.1611552

[4] G. Kaur, P. S. Matreja, A. Singh, and H. Sciences, "To Study the Level of Stress in Students in Professional School to Study the Level of Stress in Students in Professional School," no. September, 2015.

[5] A. M. Goff, "Stressors, academic performance, and learned resourcefulness in baccalaureate nursing students," Int. J. Nurs. Educ. Scholarsh., vol. 8, no. 1, 2011, https://doi.org/10.2202/1548-923x.2114

[6] C. Makwanya and O. Oni, "E-Books preference compared to print books based on student perceptions: A case of university of fort hare students," Int. J. Interact. Mob. Technol., vol. 13, no. 12, pp. 236-245, 2019. https://doi.org/10.3991/ijim.v13i12.10840

[7] R. S. Malik, "Educational Challenges in 21St Century and Sustainable Development," J. Sustain. Dev. Educ. Res., vol. 2, no. 1, p. 9, 2018, doi: 10.17509/jsder.v2i1.12266.

[8] R. Rani, "ICT (Information Communication Technology) in Teacher Education," Shikshan Anveshika, vol. 7, no. 2, p. 126, 2017, https://doi.org/10.5958/2348$\underline{7534.2017 .00025 .3}$

[9] L. Benedetto, P. Cremonesi, and M. Parenti, "A virtual teaching assistant for personalized learning," arXiv, no. June, 2019.

[10] A. Ali Ahmed Al-Rawafi and Syihabuddin, "Indonesian Language Learning Difficulties: A Linguistic Perspective,” no. July, 2019, https://doi.org/10.2991/upiupsi-18.2019.2

[11] R. Rianto, A. B. Mutiara, E. P. Wibowo, and P. I. Santosa, "Improving the Accuracy of Text Classification using Stemming Method, A Case of Informal Indonesian Conversation," pp. 1-10, 2020.

[12] M. S. Nazir et al., "Language Variations Found in The Interaction Between Buyer-Seller at Bunder Market Sragen," Spectrochim. Acta - Part A Mol. Biomol. Spectrosc., vol. 192, no. 4, pp. 121-130, 2018.

[13] G. C. Hansen, K. H. Falkenbach, and I. Yaghmai, "Voice recognition system.," Radiology, vol. 169, no. 2, p. 580, 1988, https://doi.org/10.1148/radiology.169.2.3175016

[14] C. Paier, "Implementing and Analysing Interactive Recommender Interfaces," no. September, 2018.

[15] E. Adamopoulou and L. Moussiades, An Overview of Chatbot Technology, vol. 584 IFIP, no. May. Springer International Publishing, 2020.

[16] E. Adamopoulou and L. Moussiades, "Chatbots: History, technology, and applications," Mach. Learn. with Appl., vol. 2, no. November, p. 100006, 2020, https://doi.org/10.1016/ j.mlwa.2020.100006

[17] M. M. Yulianto, R. Arifudin, and A. Alamsyah, "Autocomplete and Spell Checking Levenshtein Distance Algorithm to Getting Text Suggest Error Data Searching in Library," Sci. J. Informatics, vol. 5, no. 1, p. 75, 2018, https://doi.org/10.15294/sji. v5i1.14148

[18] N. Desai and M. Narvekar, "Normalization of noisy text data," Procedia Comput. Sci., vol. 45, no. C, pp. 127-132, 2015, https://doi.org/10.1016/j.procs.2015.03.104

[19] P. (Adam M. U. Kobzdej, D. Waligóra, K. Wielebińska, and M. Paprzycki, "Parallel Application of Levenshtein Distance to Establish Similarity Between Strings," no. May, 2014. 
[20] M. E. W. Putra and I. S. Suwardi, "Structural Off-line Handwriting Character Recognition Using Approximate Subgraph Matching and Levenshtein Distance," Procedia Comput. Sci., vol. 59, no. Iccsci, pp. 340-349, 2015, https://doi.org/10.1016/j.procs.2015.07.529

[21] R. Haldar and D. Mukhopadhyay, "Levenshtein Distance Technique in Dictionary Lookup Methods: An Improved Approach," no. January 2011, 2011, [Online]. Available: http://arxiv.org/abs/1101.1232.

[22] Maamoun M Al-Aynati and Katherine A Chorneyko, "Comparison of voice-automated transcription and human transcription in generating pathology reports," PubMed, vol. 127, no. 6, pp. 721-727, 2003. https://doi.org/10.5858/2003-127-721-covtah

\section{$9 \quad$ Authors}

Dwijoko Purbohadi is a Doctor of Information Technology, Associate Professor of Information Technology Department. Muhammadiyah Yogyakarta, DI Yogyakarta Indonesia. He obtained his master and doctoral degrees from Gajah Mada University Indonesia. Currently he is focusing on research in the field of educational technology. Email: purbohadi@yahoo.com.

Silvia Afriani is a Programmer on Information Technology Department Universitas Muhammadiyah Yogyakarta, DI Yogyakarta Indonesia. She also works as a technical support in e-learning research and development, also in this department. Email: afrianisilvia8@gmail.com

Nicko Rachmanio is a Medical Doctor of Medical Doctor Profession Education Department, Universitas Muhammadiyah Yogyakarta, DI Yogyakarta Indonesia. He also a surgeon specialist at the Muhammadiyah Hospital. Email: nicko_rachmanio@umy.ac.id

Arlina Dewi is a Doctor in Public Health. She received Ph.D. from Gadjah Mada University Indonesia. She is Head of Hospital Management Master's Degree Program, Universitas Muhammadiyah Yogyakarta, DI Yogyakarta Indonesia. Her research area is Public Health Education. Email: dewikoen@gmail.com

Article submitted 2021-01-20. Resubmitted 2021-02-17. Final acceptance 2021-02-18. Final version published as submitted by the authors. 